\title{
Inflammatory pseudotumour of spleen
}

\section{R F T MCMAHON}

From the Department of Pathology, University of Manchester, Manchester

SUMMARY A case of inflammatory pseudotumour of spleen in which plasma cells were the predominant cell type, is described. It presented as multiple nodules in the spleen of a 37 year old woman who died of myocardial infarction, and was an incidental finding at necropsy. Plasma cells were the dominant cell type, and the admixture of other cells within the mass and the lack of a monotypic light chain/immunoglobulin phenotype on immunohistochemical analysis precluded a diagnosis of malignant disease.

The potential for misinterpretation of this lesion as a neoplasm is considerable and its recognition may therefore be of great clinical importance.

Inflammatory pseudotumours are unusual lesions which present as discrete masses at various anatomical sites, especially in the respiratory $\operatorname{tract}^{12}$ and the orbit ${ }^{3}$ but also in spinal meninges, ${ }^{4}$ gastrointestinal tract, ${ }^{56}$ soft tissues, ${ }^{7}$ heart,${ }^{8}$ liver, ${ }^{9}$ and spleen. ${ }^{10}$ They are rare in the lymphoreticular system, and when seen in such sites give rise to potential misinterpretation as a neoplastic condition. A case of inflammatory pseudotumour of the spleen, detected as an incidental finding at necropsy, is described and its differentiation from more sinister conditions is discussed.

\section{Case report}

A 37 year old woman was admitted to hospital in a collapsed state. Despite intensive resuscitative measures she died snon after admission. She had had an episode of myocardial infarction four months previously, confirmed by changes in cardiac enzyme activity and on electrocardiograms. At necropsy she weighed $90 \mathrm{~kg}$. Her heart weighed $430 \mathrm{~g}$ and contained Accepted for publication 18 February 1988 an area of white scar tissue measuring $8 \times 7 \mathrm{~cm}$ on the posterolateral wall of the left ventricle, with a zone of mottling adjacent to this in the anterolateral wall. Histologically the features of both old and recent infarction were observed. The right coronary artery was small; the circumflex branch of the left coronary artery was occluded by fresh thrombus, while the anterior descending branch showed narrowing of its lumen of more than $80 \%$. The lungs were oedematous. The gall bladder showed cholesterolosis. There was a moderate degree of lymphocytic infiltration of the thyroid gland.

The spleen weighed $380 \mathrm{~g}$. Its external surface was smooth; sectioning showed the prominence of white pulp with multiple nodules, measuring up to $1.5 \mathrm{~cm}$ in diameter, related to white pulp (figs 1 and 2). Histologically these nodules were composed mainly of plasma cells, including bi-nucleated and multinucleated forms set in a variable background (figs 3 and 4). In many areas they were associated with numerous lymphocytes and occasional larger, histiocyte-like cells. Multinucleated giant cells and ill

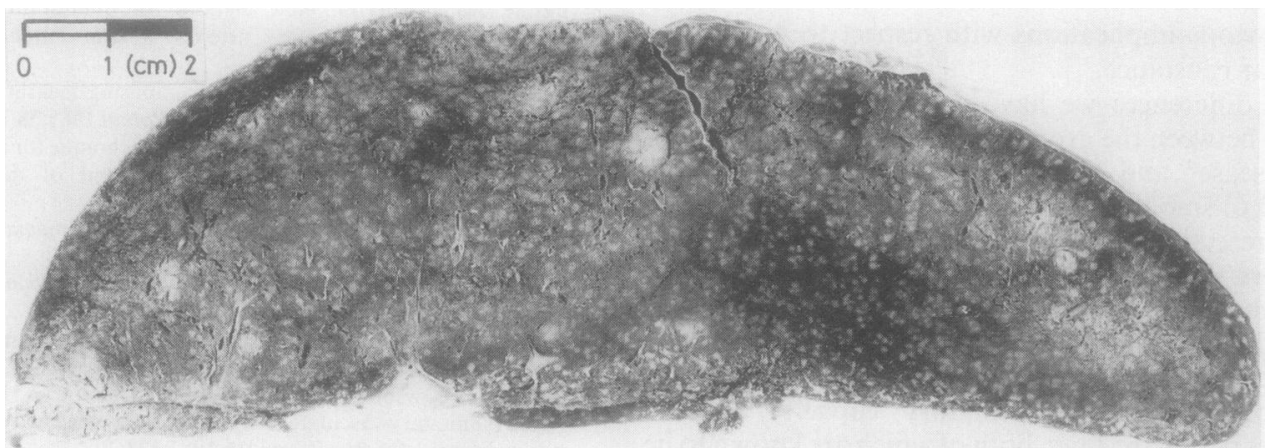

Fig 1 Spleen showing prominent Malphigian corpuscles, together with larger paler nodules of inflammatory pseudotumour. 


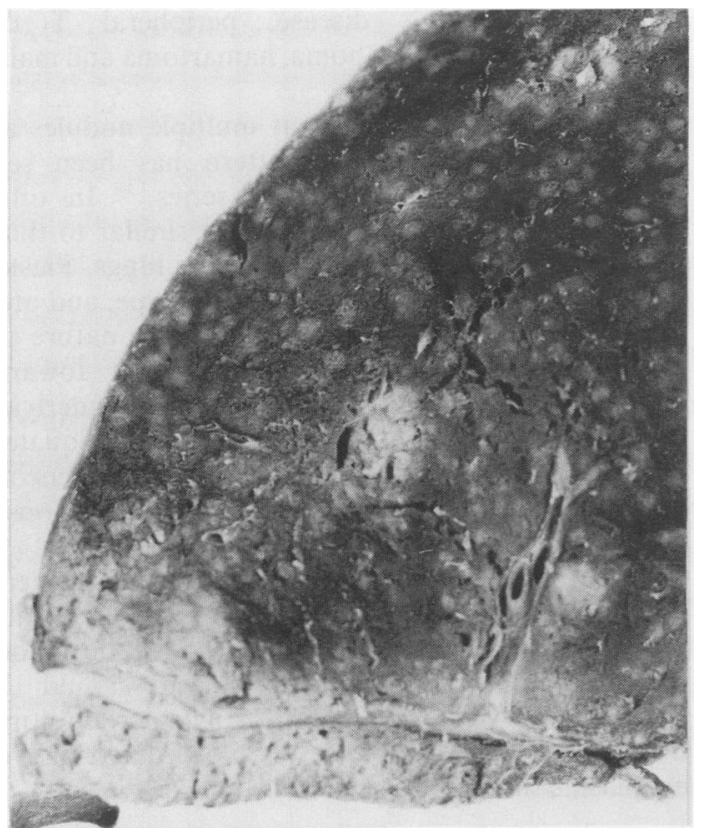

Fig 2 Higher power view of spleen showing irregular outline of inflammacory pseudotumour deposits and their relation to white pulp.

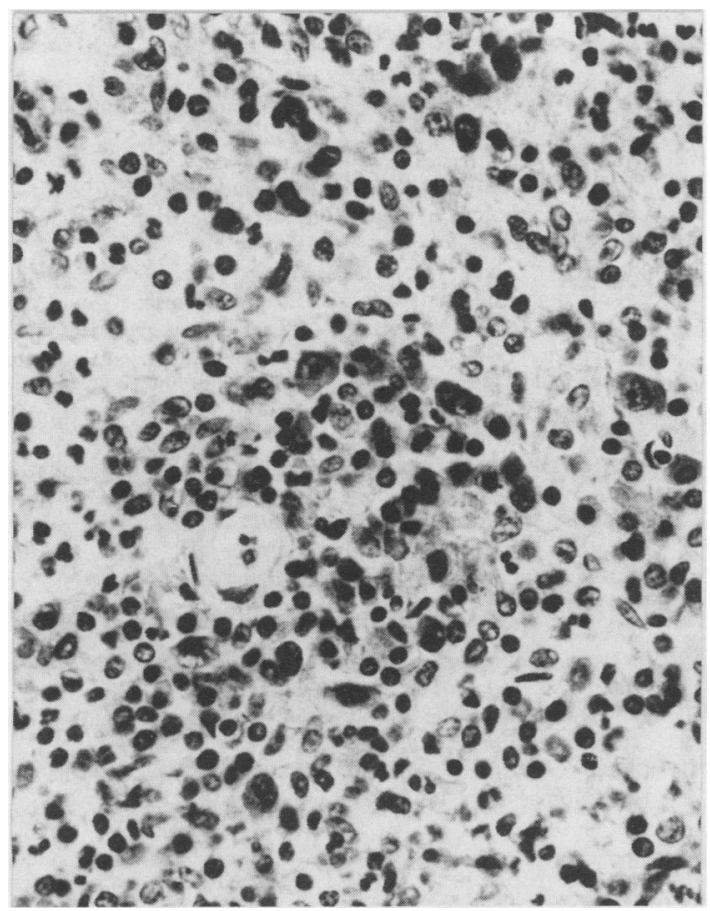

Fig 3 Nodule composed of plasma cells, lymphocytes, histiocytes and fibroblasts. (Haematoxylin and eosin)

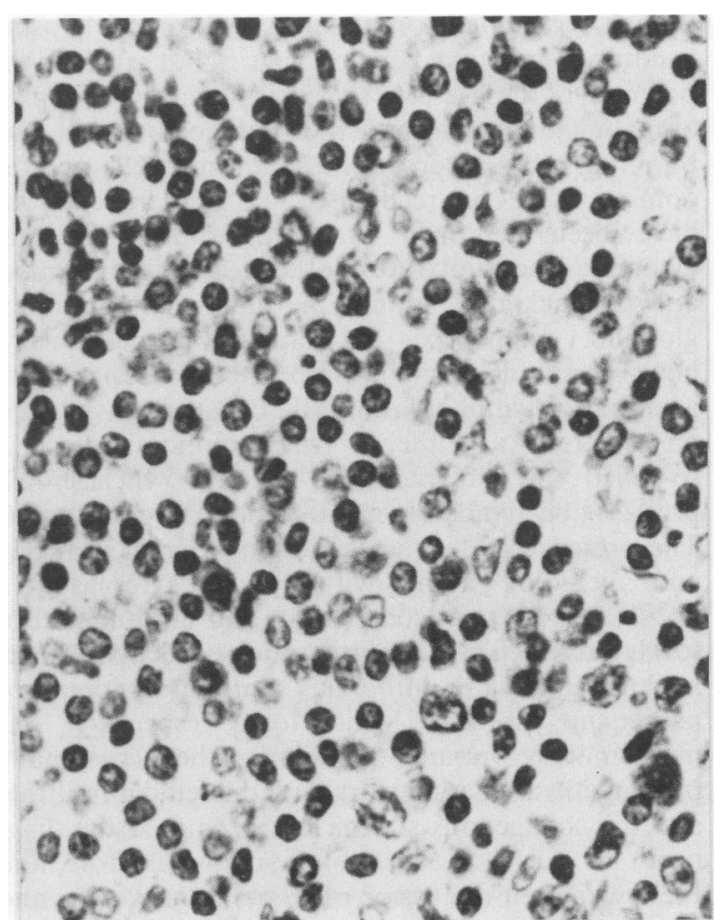

Fig 4 Higher power showing mixture of cell types-mainly lymphocytes and plasma cells. (Haematoxylin and eosin)

defined granulomata were seen; mast cells and eosinophils were noted but not in abundance. In the stroma bands of collagen and adjacent spindle shaped fibroblasts were seen while in other areas, collections of weakly periodic acid schiff positive, Congo red negative material were seen between cells. These nodules were well circumscribed and compressed the surrounding splenic parenchyma but lacked a true capsule.

Immunohistochemistry using antibodies directed against $\kappa$ and $\lambda$ light chains and G, A, M, E and D immunoglobulins by an indirect technique showed the polytypic nature of the plasma cell component of these nodules-IgG and IgM were particularly positive as were both light chains.

Lymph nodes were not enlarged and showed no histological abnormality. Sections of bone marrow from three sites (rib, vertebra, and iliac crest) were normocellular and contained no increase in plasma cells.

\section{Discussion}

Inflammatory pseudotumours have long been recognised as a non-neoplastic condition of unknown aetiology and pathogenesis. ${ }^{3}$ Their clinical importance is not related to their prognosis (almost always good, 
though occasionally progressing to chronic sclerosing conditions' and fatal haemorrhage ${ }^{11}$ ), but rather to the potential of these lesions to be misdiagnosed as benign or malignant neoplasms. The cellular component may be remarkably heterogeneous. Plasma cells are the dominant cell type recognised and thus these lesions have been described as extramedullary plasmacytomas. ${ }^{1}$ The admixture of other cells within the mass and the lack of a monotypic light chain/immunoglobulin phenotype on immunohistochemistry, however, should preclude this possibility. Lesions with a primarily lymphoplasmacytic constitution may be misconstrued as either a true lymphoma or as a so-called "pseudolymphoma", a term which should probably be avoided in most if not all circumstances. The presence of histiocytes, often in great numbers and including many with foamy cytoplasm, a fibroblastic stromal component, and granulomatous foci has resulted in the consideration of such diagnoses as histiocytoma, xanthoma, xanthogranuloma, or malignant fibrous histiocytoma-especially the inflammatory variant. ${ }^{13}$ Similarly, the occasionally prominent vascular network with the cellular infiltrate and the collagenous stroma has prompted the diagnosis of sclerosing haemangioma. Bahadori and Liebow in their discussion of $\mathbf{4 0}$ pulmonary cases and review of the literature suggest plasma cell granuloma as an alternative name to inflammatory pseudotumour in view of the predominant cell type and nonneoplastic nature of the condition. ${ }^{\prime}$ While this suggestion has been adopted in the field of respiratory pathology, it has not yet been for other anatomical sites and therefore the older term has been retained.

The only two previous cases affecting the spleen were described by Cotelingham and Jaffe. ${ }^{10}$ Both patients were men in their 60s, one with upper gastrointestinal symptoms and a vague history of tuberculosis and the other with Hodgkin's disease affecting a cervical lymph node, who was undergoing a staging laparotomy. The first patient's spleen weighed $760 \mathrm{~g}$ and contained a solitary mass measuring $11.5 \times 11 \times 11 \mathrm{~cm}$. Areas of necrosis and suppuration were seen with foreign body type giant cells, hyalinised connective tissue, spindle celled fibroblasts, and a mixture of inflammatory cells including plasma cells, polymorphs, and foamy macrophages. Occasional non-caseating epithelioid granulomata were also noted. The other patient's spleen weighed $270 \mathrm{~g}$ and contained a single nodule $3 \mathrm{~cm}$ in diameter. This showed haemorrhage and calcified necrotic debris associated with foreign body type giant cells. Fibroblasts were prominent and a cellular infiltrate of lymphocytes, polymorphs, and plasma cells was present. No granulomata were identified in this case, a feature sometimes seen in spleens of patients with Hodgkin's disease. Their differential diagnoses included Hodgkin's disease, peripheral $T$ cell lymphoma, pseudolymphoma, hamartoma and malignant fibrous histiocytoma.

Our case is unusual in that multiple nodules are present, although such a pattern has been seen occasionally in the pulmonary series. ${ }^{11}$ In other respects, however, these nodules are similar to those described previously, especially in the lungs. Plasma cells are the single most important cell type, and once these have been shown to be polytypic in nature the diagnostic considerations should turn towards reactive or inflammatory conditions. The underlying causes of these lesions have never been adequately delineated and probably represent a heterogeneous group, as indicated by the variety of cellular responses described. ${ }^{10}$

These lesions are rare in the lymphoreticular system. Although this case is a description of an incidental finding at necropsy, inflammatory pseudotumour (plasma cell granuloma) of spleen should be remembered when evaluating single or multiple nodules in spleens, and the overdiagnosis of neoplasms should be avoided.

I am grateful to Dr E W Benbow for his advice and to Ms Margaret Banton for her photographic help.

\section{References}

1 Bahadori M, Liebow AA. Plasma cell granulomas of lung. Cancer 1973;31:191-208.

2 Spencer H. Plasma cell granulomas. In: Pathology of the lung. Fourth edition. Philadelphia: WB Saunders, 1985;1012-6.

3 Garner A. Pathology of pseudotumours of the orbit. J Clin Pathol 1973;26:639-48.

4 Eimoto T, Yanaka M, Kurosawa M, Ikeya F. Plasma cell granuloma (inflammatory pseudotumour) of the spinal cord meninges. Cancer 1978;41:1929-36.

5 Christensen AH, Ishak KG. Benign tumours and pseudotumours of the gallbladder. Archives of Pathology 1970;90:423-32.

6 Johnstone JM, Morson BC. Inflammatory fibroid polyp of the gastrointestinal tract. Histopathology 1978;2:349-61.

7 Kunakemakorn P, Ontai G, Balin H. Pelvic inflammatory pseudotumor: a case report. Am J Obstet Gynecol 1976;126: 286-7.

8 Gonzalez-Crussi F, Vanderbilt BL, Miller JK. Unusual intracardiac tumor in a child-inflammatory pseudotumor or "granulomatous" variant of myxoma? Cancer 1975;36: 2214-26.

9 Someren A. Inflammatory pseudotumor of liver with occlusive phlebitis. Am J Clin Pathol 1978;69:176-81.

10 Cotelingham JD, Jaffe ES. Inflammatory pseudotumor of the spleen. Am J Surg Pathol 1984;8:375-80.

11 Warter A, Satge D, Roeslin N. Angioinvasive plasma cell granulomas of the lung. Cancer 1987;59:435-43.

Requests for reprints to: Dr R F T McMahon, Department of Pathology, Stopford Building, Oxford Road, Manchester M13 9PT, England. 